\title{
PENGARUH GAYA KEPEMIMPINAN TRANSAKSIONAL DAN GAYA KEPEMIMPINAN TRANSFORMASIONAL TERHADAP KEPUASAN KERJA KARYAWAN PADA PT JASARAHARJA PUTERA
}

\author{
N. Lilis Suryani \\ Staf Pengajar Fakultas Ekonomi Universitas Pamulang \\ Email :dosen00437@unpam.ac.id
}

\begin{abstract}
Abstrak
Tujuan penelitian ini adalah untuk mengetahui pengaruh gaya kepemimpinan transaksional dan gaya kepemimpinan transformasional terhadap kepuasan kerja karyawan pada PT Jasaraharja Putera

Metodologi penelitian menggunakan deskriptif kuantitatif dengan sample 57 respondenmenggunakan uji validitas, uji realibilitas, koefisien determinasi dan uji regresi linear berganda.

Uji signifikansi simultan/bersama-sama (uji 21able21le21 F) menghasilkan nilai F hitung sebesar 29,713. Pada derajat bebas $1(\mathrm{df} 1)=$ jumlah 21 able21le $-1=3-1=2$, dan derajat bebas $2(\mathrm{df} 2)=\mathrm{n}-\mathrm{k}-1=59-2-1=56$, dimana $\mathrm{n}=$ jumlah sampel, $\mathrm{k}=$ jumlah 21able21le independen, nilai f 21able pada taraf kepercayaan signifikansi 0,05 adalah 3,16 dengam demikian $\mathrm{F}$ hitung $=29,713>\mathrm{F} 21 \mathrm{able}=3,16$ dengan tingkat signifikansi 0,000. Karena probabilitasnya signifikansi jauh lebih kecil dari sig $<0,05$, maka model regresi dapat dipergunakan untuk memprediksi kepuasan kerja karyawan PT Jasaraharja Putera atau dapat dikatakan bahwa gaya kepemimpinan transaksional dan gaya kepemimpinan transformasional secara bersama-sama berpengaruh terhadap kepuasan kerja karyawan PT Jasaraharja Putera sehingga hipotesis nol $\left(\mathrm{H}_{03}\right)$ ditolak dan $\left(\mathrm{Ha}_{3}\right)$ diterima, sehingga hipotesis ini telah teruji secara empiris.
\end{abstract}

\section{Kata Kunci : Gaya Kepemimpinan Transaksional, Gaya Kepemimpinan Transformasional dan Kepuasan Kerja}

\section{Abstract}

The purpose of this study was to determine the effect of transactional leadership style and transformational leadership style on employee job satisfaction at PT Jasaraharja Putera

The research methodology used descriptive quantitative with sample 57 respondents using validity test, reliability test, coefficient of determination and multiple linear regression test.

Simultaneous significance test (test of can le F) yields $F$ value count of 29,713. In degrees of freedom 1 (df1) = the number of cans le $-1=3-1=2$, and degrees of freedom 2 $(d f 2)=n k-1=59-2-1=56$, where $n=$ number of samples, $k=$ le independent, the value of $f$ able at the 0.05 significance level is 3.16 so $F=29.713>F$ able $=3,16$ with a significance level of 0.000. Because the probability of significance is much less than sig <0,05, regression model can be used to predict employee job satisfaction of PT Jasaraharja Putera or it can be said that transactional leadership style and transformational leadership style together influence to job satisfaction of employee PT Jasaraharja Putera so that the null hypothesis (HO3) is rejected and (Ha3) is accepted, so this hypothesis has been empirically tested.

Keywords: Transactional Leadership Style, Transformational Leadership Style of Job Satisfaction 


\section{I.Pendahuluan}

\section{A. Latar Belakang}

Perkembangan yang begitu pesat dalam duniausaha, pada satu sisi mencerminkan kesejahteraan masyarakat tetapi di sisi lain perkembangan inimenyebabkan semakin ketatnya persaingan dalam dunia usaha. Perusahaan akhirnya dihadapkanpada tuntutan untuk bekerja secara efisien, efektif, dan ekonomis, baik dalam upaya mempertahankanpasar maupun untuk mengungguli persaingan,serta harus memiliki keunggulan kompetitif sehingga pada akhirnya mampu memenangkan persaingan yang terjadi (Nugroho, 2006).

Natepana Yavirach (2012) menemukan bahwa gaya kepemimpinan transaksional berdampak lebih tinggi terhadap kepuasan kerja dibandingkan gaya kepemimpinan transformasional pada pemerintahan di Thailand, hal ini bertentangan dengan penelitian Shaukat Ali dkk (2016) menemukan bahwa kepeminpinan transformasional memiliki dampak yang lebih tinggi pada penelitian di Pakistan. Efektivitas seorang pemimpin tergantung pada kesesuaian antara pemimpin, karyawan dan kondisi perusahaan. Penerimaan seorang pemimpin sebagian besar tergantung pada gaya kepemimpinan yang digunakan sehingga timbul rasa kesetiaan dan hormat pada diri karyawan. Oleh karena itu, gaya kepemimpinan yang tepat akan memberikan kepuasan kerja bagi karyawan.

Peneliti memilih PT Jasaraharja Putera sebagai batasan ruang lingkup penelitian karena PT Jasaraharja Putera adalah salah satu perusahaan BUMN yang sedang bertransformasi untuk menghadapi persaingan ketat yang terjadi dalam dunia usaha khususnya di bidang perasuransian. PT Jasaraharja Putera merupakan perusahaan jasa yang memberikan layanan asuransi yang luas kepada masyarakat di seluruh Indonesia dengan menyediakan solusi untuk kebutuhan jasa asuransi. Motto yang dimiliki oleh PT Jasaraharja Putera adalah "Protector for Protection". PT Jasaraharja Putera telah mendapatkan kepercayaan dari para nasabah dan mitra bisnis, sehingga semakin yakin dan mampu mengibarkan diri menjadi perusahaan asuransi terkemuka di Indonesia sesuai dengan visi perusahaan.

Dari penjelasan di atas, penulis merasa tertarik untuk melakukan penelitian dengan judul: "Pengaruh Gaya Kepemimpinan Transaksional dan Gaya Kepemimpinan Transformasional terhadap Kepuasan Kerja Karyawan pada PT Jasaraharja Putera".

\section{B.Rumusan Masalah}

\begin{tabular}{|c|c|}
\hline Berdasarkan & uraian yang \\
\hline dikemukakan pada & belakang \\
\hline $\begin{array}{l}\text { masalah diatas, } \\
\text { merumuskan bebera }\end{array}$ & $\begin{array}{l}\text { maka peneliti } \\
\text { pa permasalahan }\end{array}$ \\
\hline yang dihadapi & \\
\hline Jasaraharja Putera, & \\
\hline
\end{tabular}

1. Apakah Gaya Kepemimpinan Transaksional memiliki pengaruh terhadap Kepuasan Kerja?

2. Apakah Gaya Kepemimpinan Transformasional memiliki pengaruh terhadap Kepuasan Kerja ?

3. Apakah Gaya Kepemimpinan Transaksional dan Gaya Kepemimpinan

Transformasionalmemiliki pengaruh terhadap Kepuasan Kerja? 


\section{Kerangka Berpikir}

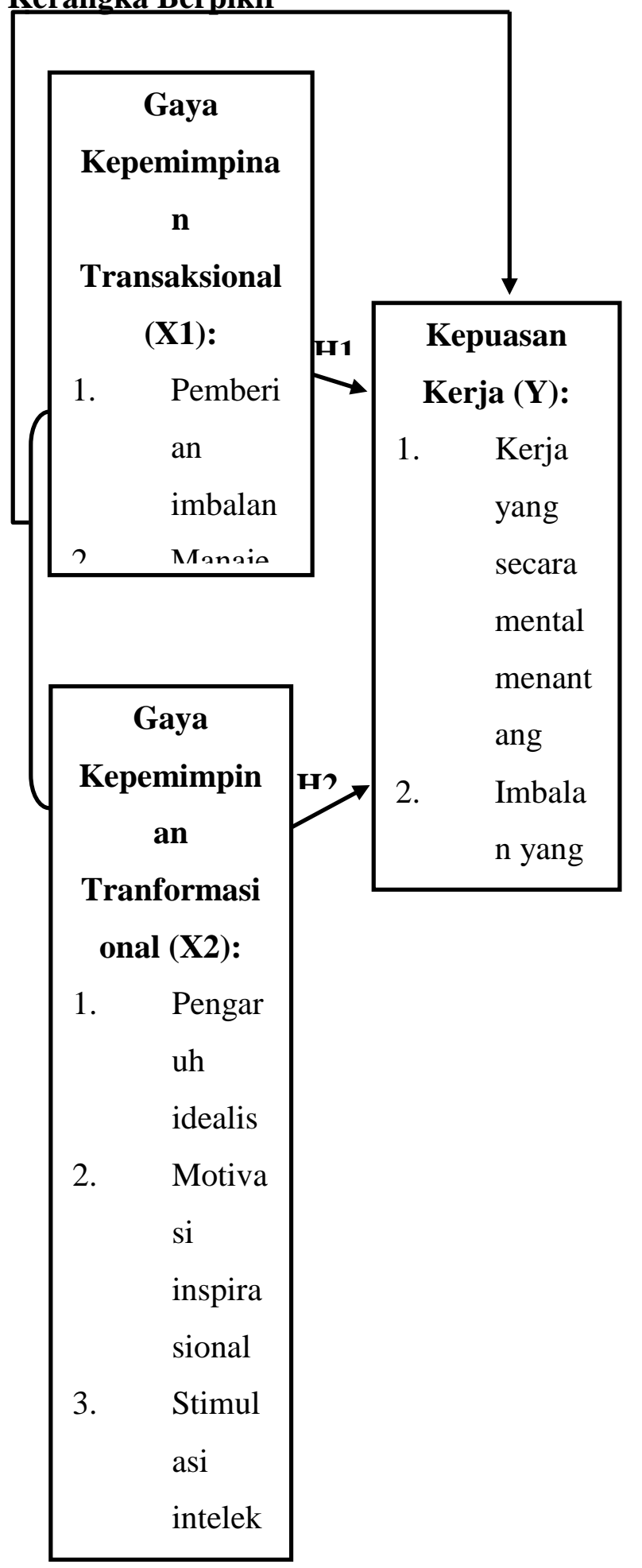

\section{Tinjauan Pustaka}

Gaya Kepemimpinan Transaksional

Salah satu teori kepemimpinan yang banyak diterapkan, terutama di perusahaan-perusahaan di Indonesia adalah teori Kepemimpinan Transaksional (transactional leadership theory). Teori ini
H3

Gambar.Skema Kerangka Berpikir mendasarkan pada asumsi bahwa kepemimpinan merupakan kontrak sosial antara pemimpin dan pengikut.

Menurut McShane \& Von Gilnow (2000:450) definisi gaya kepemimpinan transaksional adalah sebagai berikut:

"Transactional leadership helps organizations achieve their current objectives more efficiently by linking job performance to value rewards and ensuring that employees have the resources needed to get the job done".

Artinyakepemimpinan transaksional adalah kepemimpinan yang membantu organisasi mencapai tujuan mereka yang sekarang secara lebih efisien dengan menghubungkan kinerja dan imbalan yang pantas serta meyakinkan karyawan memiliki sumber daya yang cukup bagi pekerjaannya.

\section{Gaya Kepemimpinan Transformasional}

Menurut keegan dan Hartogg (2004), kepemimpinan transformasional terkait dengan identifikasi diri yang kuat, penciptaan visi bersama untuk masa depan dan hubungan antara pemimpin dan pengikut berdasarkan pada suatu hal yang lebih daripada sekedar pemberian penghargaan a bawahannya.Pemimpin transformasional juga mampu untuk memberikan semangat, mendorong dan mengilhami bawahannya untuk 
memberikan usaha ekstra untuk mencapai tujuan kelompok.

\section{Kepuasan Kerja}

Kepuasan kerja merupakan hal yang bersifat individual. Setiap individu mempunyai tingkat kepuasan yang berbeda-beda, seperti yang didefinisikan oleh Kreitner \& Kinicki (2005), bahwa kepuasan kerja sebagai efektivitas atau respons emosional terhadap berbagai aspek pekerjaan.Definisi ini mengandung pengertian bahwa kepuasan kerja bukanlah suatu konsep tunggal, sebaliknya seseorang dapat relatif puas dengan suatu aspek dari pekerjaannya dan tidak puas dengan salah satu atau beberapa aspek lainnya.

\section{Metodologi Penelitian}

Setelah dikemukakan terkait fenomena yang terjadi pada bab satu yang menjadi landasan penulis tertarik untuk mengangkat sebuah judul "Pengaruh Gaya Kepemimpinan Transaksional dan Gaya Kepemimpinan Transformasional Terhadap Kepuasan Kerja Karyawan di PT Jasaraharja Putera".

Penelitian ini dilaksanakan di PT Jasaraharja Putera,Gedung Wisma Raharja, J1. TB Simatupang Kav. 1, Cilandak Timur, Jakarta Selatan 12560, sedangkan objek yang akan penulis teliti adalah Karyawan pada PT Jasaraharja Putera.

\section{Populasi}

Populasi menurut Sugiyono (2009:80) adalah wilayah generalisasi yang terdiri atas objek atau subjek yang mempunyai kualitas dan karakteristik tertentu yang ditetapkan oleh peneliti untuk dipelajari dan kemudian ditarik kesimpulan. Populasi yang dijadikan objek dalam penelitian ini adalahseluruh karyawan PT Jasaraharja Putera di Gedung Wisma Raharja, Jl. TB Simatupang Kav. 1, Cilandak Timur, Jakarta Selatan 12560yang berjumlah 139 orang.

\section{Sampel}

Teknik pemilihan sampel dalam penelitian ini menggunakan metode simple random sampling. Menurut Sugiyono (2008:118) simple random sampling dikatakan simple (sederhana) karena pengambilan anggota sampel dari populasi dilakukan secara acak tanpa memperhatikan stara yang ada dalam populasi itu". Sampel adalah sebagian atau wakil dari populasi yang akan diteliti (Suharsimi Arikunto, 2010:109). Pengambilan sampel untuk penelitian menurut Suharsimi Arikunto (2010: 112), jika subjeknya kurang dari 100 orang sebaiknya diambil semuanya, jika subjeknya besar atau lebih dari 100 orang dapat diambil $10-15 \%$ atau $20-55 \%$ atau lebih tergantung sedikit banyaknya dari:

i. Kemampuan peneliti dilihat dari waktu, tenaga dan dana

ii. Sempit luasnya wilayah pengamatan dari setiap subyek, karena hal ini menyangkut banyak sedikitnya dana

iii. Besar kecilnya resiko yang ditanggung oleh peneliti untuk peneliti yang resikonya besar, tentu saja jika samplenya besar hasilnya akan lebih baik.

Dari keseluruhan populasi semuanya berjumlah 139 orang, maka sesuai pendapat diatas jumlah sampel dalam penelitian ini dapat diambil pendapat kedua dimana pertimbangan $40 \%$ dari keseluruhan jumlah populasi diambil dari total pengembalian kuesioner, sehingga didapat jumlah sampel untuk penelitian ini :

Total sampel ; $57=139 \times 40 \%$.

\section{Skala Pengukuran}

Setiap pertanyaan kuesioner diberikan bobot dengan menggunakan skala likert. Menurut Sugiyono (2005:87), skala likert adalah alat ukur yang dipakai untuk mengukur sikap, pendapat, dan persepsi seseorang atau sekelompok orang tentang fenomena sosial. 


\section{Metode Pengumpulan Data}

Analisis data penelitian maka perlu didukung oleh data primer maupun sekunder. Menurut Husein Umnar (2013:42). Adapun pengumpulan data yang digunakan dalam penelitian ini adalah menurut sugiyono (2008:137) adalah sebagai berikut:Kuesioner, Observasidan Wawancara

\section{Defenisi dan Pengukuran Variabel}

Variabel dependen yang digunakan

adalah Kepuasan Kerja Karyawan. Variabel ini sering disebut sebagai variabel stimulus, prediktor, atecendent, merupakan variabel yang mempengaruhi atau yang menjadi sebab perubahannya atau timbulnya variabel dependen (Sugiyono, 2013:33). Variabel independen pada penelitian ini adalah gaya kepemimpan transaksional, Gaya Kepemimpinan Transaksional,

\section{Metode Analisis Data}

Dalam penelitian ini, penulis menggunakan metode deskriptif dengan jenis penelitian studi pendekatan survey. Data yang yang diperoleh kemudian diolah, dianalisis dan diproses lebih lanjut dengan dasar - dasar teori yang telah dipelajari.

\section{Uji Kualitas Data}

Uji kualitas data digunakan untuk melihat apakah data layak untuk diuji dalam penelitian. Dalam penelitian ini terdapat tiga pengujian data, uji validitas dan uji reliabilitas. Hal ini dimaksudkan agar data benar - benar baik dan layak untuk digunakan dalam penelitian ini dan memiliki hasil yang sesuai dengan empiris dan teori.

\section{a. Uji Validitas}

Menurut Sugiyono (2002: 124) uji validitas data adalah sebagai berikut, "Teknik Korelasi untuk menentukan validitas item sampai sekarang merupakan teknik yang paling banyak digunakan".

Syarat minimum untuk dianggap memenuhi syarat adalah jika $r$ hitung $=r$
tabel.Jadi, jika korelasi antara butir dengan skor total kurang dari $r$ tabel maka butir dalam instrumen tersebut dinyatakan tidak valid.

Untuk mencari nilai korelasinya penulis menggunakan rumus Pearson Product Moment sebagai berikut :

$$
r x y=\frac{n \sum x y-\sum x \sum y}{\sqrt{\left[n \sum x^{2}-\left(\sum x\right)^{2}\right]-\left[n \sum y^{2}-\left(\sum y\right)^{2}\right]}}
$$

Keterangan :

$\mathrm{x}_{1}$ : : Variabel independen Gaya Kepemimpinan Transaksional $\mathrm{x}_{2}$ : Variabel independen Gaya Kepemimpinan Transformasional y : Variabel dependen Kepuasan Kerja

n : Banyak sampel

suatu item Instrumen dianggap valid jika memenuhi criteria sebagai berikut:

1) Jika nilai $r$ hitung $>r$ tabel, maka item pertanyaan atau pernyataan angket dinyatakan valid.

2) Jika nilai $r$ hitung $<r$ tabel, maka item pertanyaan atau pernyataan dinyatakan tidak valid.

\section{b. Uji Reliabilitas}

Uji reliabilitas dilakukan terhadap pertanyaan yang telah valid. Rumus yang dipakai adalah untuk menguji reliabilitas dalam penelitian adalah Cronbach' Alpha yang penyelesaianya dilakukan dengan membandingkan antara $r$ hitung dan $r$ table.

Kriteria untuk dianggap reliabel adalah :

- Jika $r_{\text {hitung/cronbach positif, serta }}$ $\mathrm{r}_{\text {cronbach }} \geq \mathrm{r}_{\text {tabel }}$, maka butir atau item pernyataan dinyatakan reliabel.

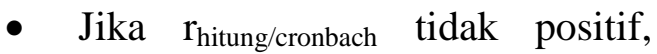
serta $r_{\text {cronbach }}<r_{\text {tabel }}$, maka butir atau item pernyataan tidak reliabel. 


\section{Analisis Regresi Linear Berganda}

Sugiyono (2012:192), analisis regresi linear digunakan untuk melakukan prediksi bagaimana perubahan nilai variabel dependen, bila nilai variabel independen dinaikan/ditunrunkan. Bentuk persamaan dari regresi linear berganda yaitu :

$$
\begin{aligned}
& \mathrm{Y}=\mathrm{a}+\mathrm{b} 1 \mathrm{X} 1+\mathrm{b} 2 \mathrm{X} 2+\mathrm{e} \\
& \text { Dimana : } \\
& \mathrm{Y}=\text { Kepuasan kerja } \\
& \text { karyawan } \\
& \text { a } \quad=\text { konstanta } \\
& \mathrm{b}_{1} \mathrm{~b}_{2} \quad=\text { Koefisien Regresi } \\
& \mathrm{X}_{1} \mathrm{X}_{2}=\text { Variabel Independen, } \\
& \text { yang terdiri dari gaya } \\
& \text { kepemimpinan } \\
& \text { Transaksional dangaya } \\
& \text { kepemimpinan } \\
& \text { transformasional. } \\
& \text { e }=\text { error item }
\end{aligned}
$$

\section{Analisis Korelasi Berganda}

Analisis ini digunakan untuk melihat kekuatan hubungan antara variabel X (Gaya Kepemimpinan Transaksional dan Gaya Kepemimpinan Transformasional) dengan variabel $\mathrm{Y}$ (Kepuasan Kerja Karyawan). Analisis korelasi berganda dapat dicari dengan rumus :

$$
R_{y(1,2,3)}=\frac{\mathrm{b}_{1} \sum \mathrm{X}_{1} \mathrm{Y}+\mathrm{b}_{2} \sum \mathrm{X}_{2}}{\sum \mathrm{Y}^{2}}
$$

Dimana :

$$
\begin{aligned}
& \mathrm{b}_{1} \mathrm{~b}_{2}=\text { Koefisien korelasi } \\
& \mathrm{X}_{1} \mathrm{X}_{2}=\text { Variabel Independen, yang } \\
& \text { terdiri dari gaya kepemimpinan } \\
& \text { transaksional dan gaya } \\
& \text { kepemimpinan transformasional } \\
& \mathrm{Y}=\text { Variabel Dependen yaitu } \\
& \text { Kepuasan kerja karyawan }
\end{aligned}
$$

\section{Koefisien Determinasi $\left(\mathbf{R}^{2}\right)$}

Koefisien determinasi $\left(\mathrm{R}^{2}\right)$ pada intinya mengukur seberapa jauh kemampuan variabel penjelas yaitu gaya kepemimpinan transaksional $\left(\mathrm{X}_{1}\right)$, dan gaya kepemimpinan transformasional dalam menerangkan variasi variabel dependen yaitu kepuasan kerja karyawan.

$$
K d=r^{2} \times 100 \%
$$

Keterangan :

$$
\begin{aligned}
& \mathrm{Kd} \quad=\text { Koefisien Determinasi } \\
& \mathrm{r}^{2} \quad=\text { Koefisien korelasi yang } \\
& \text { dikuadratkan }
\end{aligned}
$$

\section{Pengujian Hipotesis}

Dalam penelitian ini untuk menguji hipotesis penelitian menggunakan analisis regresi linier berganda yaitu melihat pengaruh gaya kepemimpinan transaksional dan gaya kepemimpinan transformasional terhadap kepuasan kerja karyawan, persamaan matematis analisis regresi linier berganda dituliskan sebagai berikut :

$$
\mathrm{Y}=\mathrm{a}+\mathrm{b}_{1} \mathrm{X}_{1}+\mathrm{b}_{2} \mathrm{X}_{2}
$$

Dimana :

$\mathrm{Y}=$ Kepuasan kerja karyawan

$\mathrm{a}=$ konstanta

$\mathrm{X}_{1}=$ gaya kepemimpinan transaksional

$\mathrm{X}_{2}=$ gaya kepemimpinan transformasional

b1,b2 = koefisien regresi

a. Uji F (pengujian secara simultan) Menurut Imam Ghozali (2005:84), uji statistik $F$ pada dasarnya menunjukkan apakah semua variabel independen atau bebas yang dimasukkan dalam model mempunyai pengaruh secara bersamasama terhadap variabel dependen/terikat. Nilai $F_{\text {hitung }}$ dapat dicari dengan rumus:

$$
\mathrm{F}=\frac{\mathrm{R}^{2} / k}{\left(1-R^{2}\right) /(n-k-1)}
$$

Dimana :

$$
\begin{aligned}
& \mathrm{R}_{2}=\text { Koefisien determinasi } \\
& \mathrm{k}=\text { banyaknya variabel bebas } \\
& \mathrm{n}=\text { banyaknya sampel }
\end{aligned}
$$

Dasar keputusan uji F :

Jika $\mathrm{F}_{\text {hitung }}<\mathrm{F}_{\text {tabel, }}$, maka $\mathrm{H}_{\mathrm{o}}$ ditolak Jika $F_{\text {hitung }}>\mathrm{F}_{\text {tabel }}$, maka $\mathrm{H}_{\mathrm{a}}$ diterima. 
JURNAL

\section{b. Uji t (Pengujian secara parsial)}

Uji t dilakukan untuk mengetahui pengaruh masingmasing variabel independen secara parsial terhadap variabel dependen.Nilai $t_{\text {hitung }}$ dapat dicari dengan rumus :

thitung $=\frac{\mathrm{r} \sqrt{\mathrm{n}-2}}{\sqrt{1-\mathrm{r}^{2}}}$

Keterangan :

$$
\begin{array}{lll}
\mathrm{t} & =\text { Distribusi } \mathrm{t} \\
\mathrm{r} & =\text { Nilai korelasi } \\
\mathrm{n} & =\text { Jumlah data } \\
\mathrm{r}^{2} & = & \text { Koefisien } \\
\text { determinasi } &
\end{array}
$$

Jika nilai t atau signifikansi $<$ 0,05, maka dapat dikatakan bahwa terdapat pengaruh yang signifikan antara variabel bebas terhadap variabel terikat. Sedangkan, jika nilai $\mathrm{t}$ atau signifikansi $>0,05$ maka dapat dikatakan bahwa tidak ada pengaruh antara variabel bebas

\section{Hasil Penelitian Dan Pembahasan}

\section{A. Deskripsi Responden}

Kuesioner yang disebarkan 57 eksemplar, semua kuesioner memenuhi kriteria. Deskripsi responden yang menjadi subjek dalam penelitian ini terdiri dari jenis kelamin, usia, pendidikan, lama bekerja dan penghasilan.

\section{Uji Validitas}

Uji validitas dilakukan untuk mengetahui apakah alat ukur yang telah disusun benar-benar mampu mengukur apa yang harus diukur. Pengujian validitas tiap butir digunakan analisis item, yaitu

Rangkuman Hasil Empiris Penelitian
\begin{tabular}{|c|c|c|}
\hline Variabel Bebas & $\begin{array}{c}\text { Koefisien } \\
\text { Regresi }\end{array}$ & Konstanta \\
\hline $\begin{array}{c}\text { Gaya Kepemimpinan } \\
\text { Transaksional (X1) }\end{array}$ & $-\mathbf{0 , 0 7 2}$ & \multirow{2}{*}{$\mathbf{2 , 1 6 4}$} \\
\cline { 1 - 2 } $\begin{array}{c}\text { Gaya Kepemimpinan } \\
\text { Transformasional (X2) }\end{array}$ & $\mathbf{0 , 5 9 0}$ & \\
\hline
\end{tabular}

Sumber : data primer yang diolah terhadap variabel terikat.

$\mathrm{H}_{01}=0$ artinya $\mathrm{X}_{1}$ tidak berpengaruh secara signifikan terhadap Y

$\mathrm{Ha}_{1} \neq 0$ artinya $\mathrm{X}_{1}$ berpengaruh secara signifikan terhadap $Y$

$\mathrm{H}_{02}=0$ artinya $\mathrm{X}_{2}$ tidak berpengaruh secara signifikan terhadap $\mathrm{Y}$

$\mathrm{Ha}_{2} \neq 0$ artinya $\mathrm{X}_{2}$ berpengaruh secara signifikan terhadap $\mathrm{Y}$

Dasar keputusan uji :

Jika $t_{\text {hitung }}>t_{\text {tabel, }}$ dan sig $<0,05$ maka $\mathrm{H}_{0}$ ditolak dan $\mathrm{Ha}$ diterima

Jika $t_{\text {hitung }}<t_{\text {tabel, }}$ dan sig $<0,05$ maka $\mathrm{H}_{0}$ diterima dan $\mathrm{Ha}$ ditolak

\section{Operasionalisasi Variabel}

Indikator gaya kepemimpinan transaksional (X1), gaya kepemimpinan transformasional (X2) dan kepuasan kerja (Y) diambil dari teori-teori yang sudah dibahas sebelumnya.

mengkorelasikan skor tiap butir dengan skor total yang merupakan jumlah tiap skor butir (corrected item total correlation) dan nilainya dapat dilihat pada hasil pengolahan menggunakan program SPSS 22.00 pada tabel item-total statistic di kolom corrected item-total correlation. Suatu pertanyaan dinyatakan valid apabila nilai $r$ hitung yang merupakan nilai corrected item-total correlation lebih besar dari $\mathrm{r}$ tabel. Kuisioner yang dinyatakan valid berarti kuesioner tersebut benar-benar mampu mengukur apa yang harus diukur

\section{Rangkuman Hasil Empiris Penelitian}

Dari data diatas dapat dibuat persamaan regresi linear berganda sebagai berikut :

$$
\mathrm{Y}=2,164-0,072 \mathrm{X}_{1}+0,590 \mathrm{X}_{2}
$$

Dimana : 


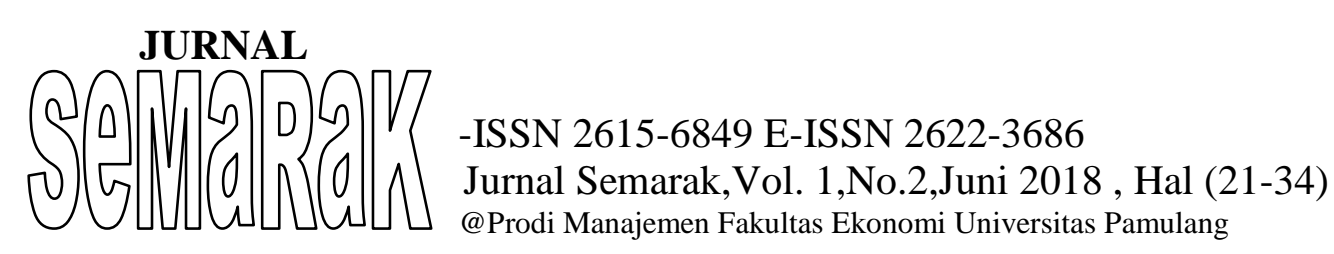

$\mathrm{Y}=$ Kepuasan kerja

karyawan

a $\quad=$ konstanta

$\mathrm{b}_{1} \mathrm{~b}_{2} \quad=$ Koefisien Regresi

$\mathrm{X}_{1}, \mathrm{X}_{2}=$ Variabel Independen, yang

terdiri dari gaya kepemimpinan

Transaksional dan gaya kepemimpinan transformasional.

Dari persamaan tersebut dapat diambil kesimpulan bahwa :

a. Konstanta sebesar 2,164 menyatakan bahwa jika ada pengaruh gaya kepemimpinan transaksional (X1) danpengaruh gaya kepemimpinan transformasional (X2) maka kepuasan kerja karyawan pada PT Jasaraharja Putera adalah sebesar 2,164 .

b. Koefisien regresi pengaruh gaya kepemimpinan transaksional (X1) sebesar - $-0,072$ menyatakan bahwa setiap penambahan 1 poin pengaruh gaya kepemimpinan transaksional (X1) akan menurunkan kepuasan kerja karyawan pada PT Jasaraharja Putera adalah sebesar 0,072 dengan anggapan pengaruh gaya kepemimpinan transformasional (X2).

c. Koefisien regresi pengaruh gaya kepemimpinan transformasional (X2) sebesar 0,590 menyatakan bahwa setiap penambahan (karena tanda positif) 1 poin pengaruh gaya kepemimpinan transformasional (X2) akan meningkatkan kepuasan kerja karyawan pada PT Jasaraharja Putera adalah sebesar 0,590 dengan anggapan pengaruh gaya kepemimpinan transaksional (X1).

Dimana pada penelitian ini ternyata variabel pengaruh gaya kepemimpinan transformasional (X2) merupakan variabel yang paling dominan / besar pengaruhnya terhadap kepuasan kerja karyawan pada PT Jasaraharja Putera, selanjutnya dipengaruhi oleh gaya kepemimpinan transaksional (X1), dimana untuk menentukan mana yang paling dominan diurutkan sampai yang terkecil dilihat dari nilai koefisien regresi yang dimiliki masing-masing variabel.

Jadi koefisien regresi yang bertanda positif (+) menandakan arah hubungan yang searah, sedangkan bila koefisien regresi bertanda negatif (-) menunjukkan arah hubungan yang berbanding terbalik antara variabel independen (X) dan variabel dependen (Y).

\section{Koefisien Korelasi Berganda}

Untuk mengetahui seberapa kuat hubungan gaya kepemimpinan transaksional dan gaya kepemimpinan transformasional terhadap kepuasan kerja karyawan, maka penulis menggunakan perhitungan dengan SPSS 22.0. untuk lebih jelasnya dapat dilihat dari tabel dibawah ini :

\section{Hasil Pengujian Koefisien Korelasi Berganda}

Model Summary ${ }^{b}$

\begin{tabular}{|c|c|c|c|c|c|c|c|c|c|c|}
\hline \multirow[b]{2}{*}{ Model } & \multirow[b]{2}{*}{$\mathrm{R}$} & \multirow[b]{2}{*}{$\begin{array}{c}\mathrm{R} \\
\text { Square }\end{array}$} & \multirow[b]{2}{*}{$\begin{array}{l}\text { Adjusted R } \\
\text { Square }\end{array}$} & \multirow{2}{*}{$\begin{array}{l}\text { Std. Error } \\
\text { of the } \\
\text { Estimate }\end{array}$} & \multicolumn{5}{|c|}{ Change Statistics } & \multirow[b]{2}{*}{$\begin{array}{l}\text { Durbin- } \\
\text { Watson }\end{array}$} \\
\hline & & & & & $\begin{array}{l}\text { R Square } \\
\text { Change }\end{array}$ & $\begin{array}{c}\mathrm{F} \\
\text { Change }\end{array}$ & df1 & df2 & $\begin{array}{c}\text { Sig. F } \\
\text { Change }\end{array}$ & \\
\hline 1 &, $792^{\mathrm{a}}$ &, 627 &, 606 &, 23843 &, 627 & 29.713 & 3 & 53 &, 000 & 1,659 \\
\hline
\end{tabular}

a. Predictors: (Constant), Gaya Kepemimpinan Transformasional, Gaya Kepemimpinan Transaksional

b. Dependent Variable: Kepuasan Kerja Karyawana

Sumber : data primer yang diolah

Hubungan variabel gaya kepemimpinan transaksional dan gaya kepemimpinan

transformasional

terhadap kepuasan kerja karyawan 
adalah 0,792. Artinya hubungan antara gaya kepemimpinan transaksional dan gaya kepemimpinan transformasional terhadap kepuasan kerja karyawan mempunyai korelasi yang kuat (menurut Sugiyono, 2008). Korelasi yang positif menunjukkan bahwa variabel $\mathrm{X}$ dan $\mathrm{Y}$ mempunyai hubungan yang kuat dan searah, artinya apabila gaya kepemimpinan transaksional dan gaya kepemimpinan transformasional meningkat maka akan diikuti oleh peningkatan kepuasan kerja karyawan, sebaliknya apabila gaya kepemimpinan transaksional, gaya kepemimpinan transformasionalmenurun maka akan diikuti oleh penurunan kepuasan kerja karyawan.

\section{Koefisien Determinasi (R2)}

\section{Hasil Pengujian untuk Uji Koefisien Determinasi (R Square)} Model Summary ${ }^{\text {b }}$

\begin{tabular}{|c|c|c|c|c|c|c|c|c|c|c|}
\hline \multirow[b]{2}{*}{ Model } & \multirow[b]{2}{*}{$\mathrm{R}$} & \multirow[b]{2}{*}{$\begin{array}{c}\mathrm{R} \\
\text { Square }\end{array}$} & \multirow[b]{2}{*}{$\begin{array}{l}\text { Adjusted R } \\
\text { Square }\end{array}$} & \multirow{2}{*}{$\begin{array}{l}\text { Std. Error } \\
\text { of the } \\
\text { Estimate }\end{array}$} & \multicolumn{5}{|c|}{ Change Statistics } & \multirow[b]{2}{*}{$\begin{array}{l}\text { Durbin- } \\
\text { Watson }\end{array}$} \\
\hline & & & & & $\begin{array}{l}\text { R Square } \\
\text { Change }\end{array}$ & $\begin{array}{c}\mathrm{F} \\
\text { Change }\end{array}$ & df1 & $\mathrm{df} 2$ & $\begin{array}{c}\text { Sig. F } \\
\text { Change }\end{array}$ & \\
\hline 1 &, $792^{\mathrm{a}}$ &, 627 & ,606 &, 23843 &, 627 & 29.713 & 3 & 53 &, 000 & 1,659 \\
\hline
\end{tabular}

a. Predictors: (Constant), Gaya Kepemimpinan Transformasional, Gaya Kepemimpinan Transaksional b. Dependent Variable: Kepuasan Kerja Karyawana

Sumber : data primer yang diolah

Korelasi itu berarti hubungan, begitu pula analisis korelasi yaitu suatu analisis yang digunakan untuk melihat hubungan antara dua variabel. Nugroho (2005), uji korelasi tidak membedakan jenis variabel (tidak ada variabel dependen maupaun independen). Nilai korelasi dapat dikelompokkan dalam Nugroho, (2005) sebagai berikut : $0,41 \mathrm{~s} / \mathrm{d}$ 0,70 korelasi keeratan kuat, $0,71 \mathrm{~s} / \mathrm{d} 0,90$ sangat kuat dan 0,91 s/d 0,99 sangat kuat sekali dan jika 1 berarti sempurna, pada hasil penelitian ditemukan bahwa hubungan antara pengaruh gaya kepemimpinan transaksional dan pengaruh gaya kepemimpinan transformasional terhadap kepuasan kerja karyawan pada PT Jasaraharja Putera adalah sangat kuat sebesar $(r=0,792)$.

Koefisien determinasi atau angka $\mathrm{R}$ square adalah sebesar 0,627 Nugroho (2005), menyatakan untuk regresi linear berganda sebaiknya menggunakan $\mathrm{R}$ square yang sudah disesuaikan atau tertulis Adjusted $\mathrm{R}$ square, karena disesuaikan dengan jumlah variabel independen yang digunakan, dimana jika variabel independent 1 (satu) maka menggunakan $\mathrm{R}$ square dan jika telah melebihi 1 (satu) menggunakan adjusted $\mathrm{R}$ square . Adjusted R square adalah sebesar 0,606 hal ini berarti $60,6 \%$ dari variasi variabel dependent kepuasan kerja karyawan pada PT Jasaraharja Putera yang dapat dijelaskan oleh variabel independent gaya kepemimpinan transaksional dan gaya kepemimpinan transformasional sedangkan sisanya sebesar 0,363 atau $36,3 \%$ (1- 0,627 atau $100 \%$ - 62,7\%) dijelaskan oleh Variabel-variabel lain diluar variabel yang ada. Nilai R Square berkisar pada angka 0 sampai 1 , dengan catatan semakin kecil angka $\mathrm{R}$ square, semakin lemah hubungan kedua variabel (begitu juga sebaliknya).

\section{Pengujian Hipotesis}

\section{Uji F (pengujian secara simultan)}

Uji F untuk menentukan apakah secara serentak / bersama-sama variabel independent mampu menjelaskan variabel dependen dengan baik atau apakah variabel 
independen secara bersama-sama mempunyai pengaruh yang signifikan terhadap variabel dependen. Pada tabel Anova dapat dilihat pengaruh variabel independent pengaruh gaya kepemimpinan transaksional dan pengaruh gaya kepemimpinan transformasional terhadap variabel dependen kepuasan kerja karyawan pada PT Jasaraharja Putera secara simultan/bersama.

\section{Hasil Pengujian untuk Uji Simultan dengan F-test}

\begin{tabular}{|c|c|c|c|c|c|c|}
\hline \multicolumn{7}{|c|}{ ANOVA $^{a}$} \\
\hline & & Sum of Squares & Df & Mean Square & $\mathrm{F}$ & Sig. \\
\hline \multirow[t]{3}{*}{1} & Regression & 5,067 & 3 & \multirow{3}{*}{$\begin{array}{r}1,689 \\
, 057\end{array}$} & \multirow[t]{3}{*}{29,713} & \multirow[t]{3}{*}{, $000^{\mathrm{b}}$} \\
\hline & Residual & 3,013 & 53 & & & \\
\hline & Total & 8,080 & 56 & & & \\
\hline
\end{tabular}

\section{Sumber : data primer yang diolah}

Uji signifikansi simultan/bersamasama (uji statistik F) menghasilkan nilai $\mathrm{F}$ hitung sebesar 29,713. Pada derajat bebas $1($ df1 $)=$ jumlah variabel $-1=3-1=2$, dan derajat bebas $2(\mathrm{df} 2)=\mathrm{n}-\mathrm{k}-1=59-2-$ $1=56$, dimana $\mathrm{n}=$ jumlah sampel, $\mathrm{k}=$ jumlah variabel independen, nilai $f$ tabel pada taraf kepercayaan signifikansi 0,05 adalah 3,16 dengam demikian $\mathrm{F}$ hitung = 29,713> $\mathrm{F}$ tabel $=3,16$ dengan tingkat signifikansi 0,000 . karena probabilitasnya signifikansi jauh lebih kecil dari sig < 0,05, maka model regresi dapat dipergunakan untuk memprediksi kepuasan kerja karyawan PT Jasaraharja Putera atau dapat dikatakan bahwa gaya kepemimpinan transaksional dan gaya kepemimpinan transformasional secara bersama-sama berpengaruh terhadap kepuasan kerja karyawan PT Jasaraharja Putera sehingga hipotesis nol $\left(\mathrm{H}_{03}\right)$ ditolak dan $\left(\mathrm{Ha}_{3}\right)$ diterima, sehingga hipotesis ini telah teruji secara empiris.

\section{Uji t (Pengujian secara parsial)}

Uji statistik $t$ pada dasarnya digunakan untuk melihat pengaruh variabel independen terhadap variabel dependen secara parsial. Dimana pada penelitian ini untuk melihat pengaruh gaya kepemimpinan transaksional dan gaya kepemimpinan transformasional terhadap kepuasan kerja karyawan Pada PT Jasaraharja Putera secara parsial / individual.

Hasil Pengujian untuk Uji Parsial dengan t-test

\begin{tabular}{|c|c|l|l|}
\hline Variabel Bebas & t-hitung & Probabilitas & Keterangan \\
\hline $\begin{array}{c}\text { Gaya Kepemimpinan } \\
\text { Transaksional (X1) }\end{array}$ & $-\mathbf{0 , 7 5 1}$ & $\mathbf{0 , 4 5 6}$ & Tidak Signifikan \\
\hline $\begin{array}{c}\text { Gaya Kepemimpinan } \\
\text { Transformasional (X2) }\end{array}$ & $\mathbf{8 , 5 9 9}$ & $\mathbf{0 , 0 0 0}$ & Signifikan \\
\hline \multicolumn{3}{r}{ T table $=\mathbf{2 , 0 0 3}(\alpha: \mathbf{5 \%})$} \\
\hline
\end{tabular}

Sumber : data primer yang diolah

Berdasarkan analisis di atas disimpulkan bahwa gaya kepemimpinan transaksional tidak berpengaruh signifikan terhadap kepuasan kerja karyawan Pada PT Jasaraharja Putera sehingga hipotesis 1 
Ditolak. Dan gaya kepemimpinan transformasional berpengaruh signifikan terhadap kepuasan kerja karyawan Pada PT Jasaraharja Putera sehingga hipotesis 2 Diterima.

\section{Kesimpulan}

Pada bagian ini akan disimpulkan hasil penelitian yang telah dilalukan yang dianggap bermanfaat bagi PT Jasaraharja Putera. Penelitian ini mencoba meneliti mengenai pengaruh gaya kepemimpinan transaksional dan gaya kepemimpinan transformasional terhadap kepuasan kerja karyawan PT Jasaraharja Putera. Berdasarkan uraian dan penjelasan yang telah dikemukakan pada bab-bab sebelumnya, maka ditarik kesimpulan sebagai berikut :

1. Pada PT Jasaraharja Putera gaya kepemimpinan transaksional tidak berpengaruh signifikan terhadap kepuasan kerja karyawan.kepemimpinan transaksional adalah kepemimpinan yang membantu organisasi mencapai tujuan mereka yang sekarang secara lebih efisien dengan menghubungkan kinerja dan imbalan yang pantas serta meyakinkan karyawan memiliki sumber daya yang cukup bagi pekerjaannya. Pada perusahaan PT Jasaraharja Putera kompensasi keuangan merupakan bukan ukuran kepuasan kerja.

2. Pada PT Jasaraharja Putera gaya kepemimpinan transformasional berpengaruh signifikan terhadap kepuasan kerja karyawan.Pemimpin transformasional juga mampu untuk memberikan semangat, mendorong dan mengilhami bawahannya untuk memberikan usaha ekstra untuk mencapai tujuan kelompok. Peran pemimpin didalam melaksanakan pekerjaannya menjadi salah satu faktor yang mempengaruhi pada PT Jasarahara Putera.
3. Secara bersama-sama gaya kepemimpinan transaksional dan gaya kepemimpinan transformasional berpengaruh signifikan terhadap kepuasan kerja karyawan pada PT Jasaraharja Putera.

\section{Daftar Pustaka}

A.A Sagung Diah Putri Utami dkk. 2015. Pengaruh Kepemimpinan Transaksional dan Stress Kerja terhadap Kepuasan Kerja Karyawan pada PLN PerseroBali Selatan. E-Jurnal Manajemen Unud, Vol.4, No.4, 2015: 960-97.

Didit Setyo Pambudi. 2016. Pengaruh Gaya Kepemimpinan Transformasional tergadap Kinerja Karyawan Melalui Kinerja Karyawan Sebagai Variable Mediasi (Studi pada Karyawan PT Telkom Indonesia Witel Jatim Selatan Malang). Jurnal Administrasi Bisnis (JAB) Vol.39 No.1Oktober 2016.

Husein Umar. 2005. Metode Penelitian untuk Skripsi dan Tesis Bisnis.Jakarta:Raja Grafindo Persada.

Imam Ghozali, 2001. Aplikasi Analisis Multivariate dengan Program SPSS. Semarang: Badan Penerbit Univ Diponegoro.

J. Supranto. 2000. Statistik: Teori dan Aplikasi. Jakarta: Erlangga.

Kreitner, Robert \& Kinicki., Anggelo. 2005. Perilaku Organisasi. Jakarta : Salemba Empat.

Kuncoro, Mudrajad. 2003. Metode Riset untuk Bisnis dan Ekonomi. Jakarta: Erlangga. 
Lerbin R. Aritonang. 2000. Penelitian Pemasaran. Jakarta: Universitas Tarumanagara.

Mangkunegara, Anwar Prabu. 2005. Evaluasi Kinerja SDM. Bandung : Refika Aditama

Mohammad As'ad, 2004. Seri Ilmu Sumber Daya Manusia: Psikologi Industri. Edisi Keempat. Yogyakarta: Liberty.

Natepanna Yavirach . 2012. The Impact of Transformational and Transactional Leadership to subordinates, Job Satisfaction, Organizational, Commitment Affect to Team Effectiveness. /www.ssrn.com/abstract $=2159035$.

Rifai George, 2012.Prinsip-prinsip Pengelolaan Strategi Bisnis. Jakarta: PT Gramedia Pustaka Utama.

Schermerhon, Hunt \& Osborn. 2005. Organizational Behavior. Ninth Edition. New York: John Wiley \& Sons, Inc.

Shaukat Ali et,al (2016).Effectof Transformational Leadership on Job Satisfaction and Organizational

Commitment../www.ssrn.com/ abstract $=2713386$.

Shriberg, Arthut, David L. Lloyd, Carol. 2002. Practicing Leadership. New York: John Wiley \& Sons, Inc.
Sudaryono, 2014.Leadership : Teori dan Praktek Kepemimpinan. Jakarta : Lentera Ilmu Cendekia.

Sunardi dan Anita Primastiwi, 2012.Bisnis Pengantar (Konsep, Strategi dan Kasus). Yogyakarta: CAPS.

Suparyadi, 2015.Manajemen Sumber Daya Manusia - Menciptakan Keunggulan Bersaing Berbasis Kompetensi SDM. Yogyakarta: $\mathrm{CV}$. Andi Offset.

Sugiyono, 2006. Statistika untuk Penelitian, Bandung: Alfabeta.

Stoner, James AF, Freeman, R. Edward, Gilbert, Daniel R. 2000. Manajemen. Jakarta: Prenhallindo.

T. Hani Handoko, 2001, Manajemen Personalia dan SDM, edisi kedua, Yogyakarta, BPFE

Veithzal Rivai, 2004. Manajemen Sumber Daya Manusia untuk perusahaan. Jakarta: RajaGrafindo Persada.

Wijayanto Dian, 2012.Pengantar Manajemen. Jakarta: PT Gramedia Pustaka Utama.

Wiratna, Sujarweni V, 2014.Metodologi Penelitian. Yogyakarta: Pustakabarupress.

Wirawan, 2014.Kepemimpinan: Teori. Psikologi, Perilaku Organisasi, Aplikasi dan Penelitian. Jakarta: RajaGrafindo Persada.

Yulk, Gary. 2003. Kepemimpinan dalam Organisasi. Jakarta: Indeks. 